\title{
Identification of superior spring durum wheat genotypes under irrigated and rain-fed conditions
}

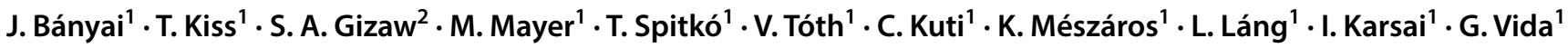

Received: 5 November 2019 / Accepted: 24 March 2020 / Published online: 10 April 2020

(c) The Author(s) 2020

\begin{abstract}
An important objective of wheat improvement programmes is to breed varieties for high yield in optimum conditions and for minimum yield reduction under stress-prone conditions such as heat and drought. Analyses of yield and its components in multiple years allow a comprehensive and comparative understanding of genetic yield potential and stress-tolerance mechanisms in the study germplasm. The present study was carried out to evaluate performance of elite varieties and landraces of spring durum wheat under different water regimes, determine the repeatability of the examined traits, and identify superior genotypes for their potential use in breeding for drought tolerance. A total of 97 accessions of spring durum wheat (T. durum Desf.) were evaluated under rain-fed and well-watered conditions in the nursery of the Centre for Agricultural Research at Martonvásár, Hungary (2011-2013). The experiments were laid out in an unbalanced, incomplete alpha lattice block design. The trait with the lowest broad-sense repeatability was seed length $(0.075)$, while high $\mathrm{h}^{2}$ values were observed for heading date $(0.89)$, thousand-grain weight $(0.85)$ and the protein content $(0.85)$. Grain yield showed moderate level of repeatability $(0.53)$ across the three years. The principal component analysis revealed that grain yield $(\mathrm{t} / \mathrm{ha})$ is positively associated with the fertile tiller number, chlorophyll content values at early waxy ripeness stages and plant height. Based on biplot analysis, 'DP-133', 'DP-017' and 'DP-061' proved to be the best durum cultivars in terms of yield whereas genotypes 'DP-011', 'DP$185^{\prime}$, 'DP-126' and 'DP-136' preceded them with their good yield stability.
\end{abstract}

Keywords Drought stress $\cdot$ Repeatability $\cdot$ Spring durum wheat $\cdot$ Stability $\cdot$ Yield

\section{Introduction}

By 2050, there are likely to be 9 billion people on the planet and demand for cereals will increase significantly. Unfortunately, global warming is projected to rise temperatures and reduce rainfall in many parts of the world, decreasing agricultural productivity and inducing changes in plant life (Araus et al. 2002; Seguin 2010).

Electronic supplementary material The online version of this article (https://doi.org/10.1007/s42976-020-00034-z) contains supplementary material, which is available to authorized users.

$\triangle$ J. Bányai

banyai.judit@agrar.mta.hu

1 Centre for Agricultural Research, Martonvásár 2462, Hungary

2 Department of Crop and Soil Sciences, Washington State University, Pullman, WA 99164, USA
Mild water shortage causes $20-30 \%$ of yield reduction whereas severe drought stress can cause more than $70 \%$ yield reduction. Behera and Sharma (2014) ascertain that the sensitivity of wheat to moisture stress varies with soil type, temperature and weather conditions in different regions, and breeding for drought tolerance is complex due to fluctuations in the time of onset, duration and severity of moisture stress. The need to feed an ever-increasing population means that the efforts of biologists and plant breeders resemble a race to produce genotypes that have not only greater productivity but also better adaptability.

There is a general consensus that genotypes could be high yielders under both well-watered (optimum) and moisture stressed environments by possessing yield-positive and stress-adaptive traits. However, some drought tolerance mechanisms cause yield penalty under non-stress condition, as another setback for successful breeding programs, which may have achieved high tolerance (Rosielle and Hamblin 1981; Dixit et al. 2014; Spitkó et al. 2014). In addition, drought is often associated with heat stress in late spring 
affecting the plants in earlier phenophases than usual (Bányai et al. 2014; Kiss et al. 2014). It brings out morpho-anatomical, physiological and biochemical changes and reduction in yield (Ahamed et al. 2010; Pandey et al. 2014).

The important objective of wheat improvement program is to develop not only heat and drought tolerant but also high yielding and stable varieties (Sharma et al. 2013). To design experiments that will give reproducible results is difficult because of the various forms, combination and duration of the stress (Spitkó et al. 2014). Selection methods can be divided into direct selection (for performance) and indirect selection (for specific morphological, phenological or physiological characteristics that contribute to performance) under stress and non-stress conditions. Because drought and heat stresses are not a single phenomenon, selection for resistance to a complex impact is always a type of indirect selection (Haussmann et al. 2012; Habash et al. 2009). Budak et al. (2013) agreed that utilization of drought tolerant wild species and the rapid advances in molecular, biological, functional genomics, and transgenic technologies have facilitated drought-related studies. However, using physiological screening and the measurement of yield components under stress condition is still the most effective way of identifying stress-tolerant wheat lines (Balla et al. 2012). The most popular approach to breeding until now has been to select for plants with highest yield in field trials across the production zone (Tardieu and Hammer 2012). Consequently Paul et al. (2016) concluded that phenotyping protocols should include grain yield assessment when the aim is the optimization of grain yield and grain yield stability under stress conditions. It is known that the yield of each cultivar in each test environment is a mixture of environment main effect (E), genotype main effect (G) and genotype-by-environment interaction (GEI). Additive main-effects and multiplicative interaction (AMMI) is a common statistical method used to analyze regional performance trials, generally called multi-environment trials (MET), with fixed effect by applying singular value decomposition (SVD) to the residuals of linear model to decompose GEI into a sum of multiplicative terms (Gauch 1988). This method ranks genotypes based on AMMI stability value (ASV) and yield stability index (YSI). The regional performance trials tend to produce large quantities of yield data, making it difficult to understand the general pattern of the data without graphical presentation (Farshadfar et al. 2013). The most recent method, the GGE biplot model, provides breeders with a complete visual evaluation of all aspects of the data by creating a biplot that simultaneously represents both mean performance and stability (Yan and Holland 2010; Gedif and Yigzaw 2014). Analyses of performance using data from multi-year trials allow a comprehensive and comparative understanding of the evaluated germplasm and the environments where the trials were conducted. The present study was undertaken to: (1) evaluate the performance of elite varieties and landraces of durum wheat under different water regimes, aimed at enhancing productivity and determining the repeatability of the examined traits and (2) identify superior genotypes better adapted to drought conditions, therefore being useful for breeding germplasm tolerant to drought stress.

\section{Materials and methods}

\section{Plant materials}

97 accessions of durum wheat (T. durum Desf.) have been evaluated under rain-fed and well-watered conditions in the nursery of the Centre for Agricultural Research (ATK) at Martonvásár, Hungary, during the 2011, 2012 and 2013 spring cropping season. The durum wheat material includes elite varieties and landraces developed in different area (Italy, Mexico, Morocco, Spain, Syria, Tunisia, and USA) and used by breeders throughout the Mediterranean countries during the past 40 years. These materials have been selected based on a particular focus to their flowering date, with a window of six days.

\section{Experimental design and water supply to the plots}

The experiments were laid out in unbalanced incomplete alpha lattice block design with three replications for rain-fed experiment and two for well-watered. The genotypes were sown between 9 and 16 March in each year. Individual plots consisted of 8 rows, $12 \mathrm{~cm}$ apart, in $0.96 \mathrm{~m} \times 4 \mathrm{~m}$ plots. No disease was shown during growth period and weed control was made by chemical method. The soil texture of the experimental site is a chernozem with forest residues, having good water permeability. Soil moisture sensors were placed at depths of $30,60 \mathrm{~cm}$ at five points, all in the plot containing the variety 'Meridiano'. Measurements on the moisture content $(\mathrm{v} / \mathrm{v} \%)$, temperature $\left({ }^{\circ} \mathrm{C}\right)$ and electrical conductivity $(\mathrm{dS} / \mathrm{m})$ of the soil were made every hour throughout the growing season.

Based on the $\mathrm{pF}$ curve, the water stress state was associated with a value of $21.5 \mathrm{v} / \mathrm{v} \%(\mathrm{pF} 3.4)$. The change in tension was constantly monitored with an MPS- 1 tensiometer. Values of -30 to $-40 \mathrm{kPa}$ represent satisfactory water supplies for the crop, while values lower than $-40 \mathrm{kPa}$ stress the plants and irrigation is required to ensure optimum development and yields. Irrigation was carried out by means of micro-irrigation with micro-jets, which distributed a uniform quantity of water on the well-watered replications. Water supply was provided on three occasions during the 2011 growing season (at the boot stage (Z45), at flowering (Z65) and in the late milky ripening stage of development (Z77), and on four occasions during the 2012 growing season (at 
the boot stage (Z45), at $1 \frac{1}{2}$ of inflorescence emerged (Z55), at early milk (Z73) and at medium milk (Z75) plant developmental stages). In 2013, the irrigation started at booting stage (Z45) and continued regularly until the end of July to keep the soil tension around $-35 \mathrm{kPa}$. Total amount of water supplied for the well-watered treatment was $167 \mathrm{~mm}$, $222 \mathrm{~mm}$ and $224 \mathrm{~mm}$ respectively. Air temperature (min, max, mean), humidity, global radiation, wind speed and rainfall quantity were recorded daily throughout the growing season.

The chlorophyll content of the flag-leaf was measured using a SPAD-502 chlorophyll meter at the boot stage (Z45), at flowering (Z65), in the late stages of milky ripeness (Z77), at early waxy ripeness (Z83) and at the end of waxy ripeness (Z85) in ten replications per genotype for each water regime. The mean plant height was determined at the end of the physiological maturity phenophase as follows: Plant height up to flag leaf collar (FLC), to the base of the ear (BE), to the tip of the ear (TE, without awn) and the ear length (EL) in five replications. The plots were harvested at full maturity using a small-plot combine. Yield (GY) and yield components were recorded including thousand-kernel weight (TGW), seed width (SW) and seed length (SL) of the main spike, which were determined using the Marvin digital seed analyser system. Test weight (HL), gluten content $(\mathrm{G})$, protein content and sedimentation index $(\mathrm{Z})$ were also measured.

\section{Statistical analysis}

Analysis on the phenotypic data was performed for each year and for all the years combined using the linear random/mixed effect model in the Genstat 18 software package (REML-Linear Mixed Models) and GGE Biplot package in R. Interactions and correlations between the traits and treatments were determined using principal component analysis, while the best-performing genotype was selected by means of principal component biplot analysis. To validate the superiority and stability estimates, additive main effect and multiplicative interaction (AMMI) was computed using Plantbreeding package in $\mathrm{R}$ "plantbreeding", repos = "https ://r-forge.r-project.org".

\section{Results}

\section{Effect of drought stress on the plant performance}

The spring season was extremely dry in 2011 and 2012, and despite sporadic rain, the soil moisture content dropped to $18-21 \mathrm{v} / \mathrm{v} \%$; hence, the crop suffered from water deficit right up to the beginning of harvest. In addition, the booting stage was followed by high daily mean temperatures.
Analysis of variance showed a considerable amount of genotypic variability for all the traits in all the years. The effect of irrigation was also highly significant for all the traits in the two dry years. The broad-sense repeatability was estimated for 19 traits as presented in Table 1. The trait with the lowest broad-sense repeatability was seed length $(0.075)$ while heading date had the highest (0.89). Thousand-kernel weight $(0.85)$ and protein content $(0.84)$ also exhibited high repeatability values. For grain yield, a moderate level of repeatability (0.53) was identified across the three years due to the strong yearly genotype-by-environment interactions. Based on the results of combined analysis of variance, the genotype-by-treatment interaction was highly significant for grain yield as indicator of phenotypic stability.

In the principal component analysis of the relationships between the measured parameters, eigenvalue of six factors had greater than one in the rain-fed replications, which together accounted for $74.5 \%$ of the total variance. The first background variables (39.7\% of the total variance) are most strongly correlated with heading date $(\mathrm{HD} r=0.95)$ and chlorophyll content (SPAD83 $\mathrm{r}=0.95)$, and correlated with yield (GY r $=0.62)$, test weight $(\mathrm{HL} r=0.65)$ and two morphological properties (BE, TE; $r=0.64,0.62$ ). The second factor $(10.29 \%$ of the total variance) correlated with yield components (SW, SL, TGW; $r=0.54-0.57$ ), while the third background variable is showed a close correlation with SPAD values measured until the late milk stage (SPAD45, SPAD65 and SPAD77; $r=0.42-0.62$ ). Based on the factorvariable correlation pattern (Fig. 1), yield (GY) was in the same group with plant height parameters (FLC, BE and TE). Despite the high genetic variability of the length of the spike, no positive correlation with yield was achieved in any of the treatments. There were genotypes which reached a higher average yield per hectare with higher fertile tiller number.

\section{Identifying superior durum wheat genotypes under rain-fed conditions}

The first two principal components, PC1 and PC2, accounted for $45.50 \%$ and $19.93 \%$ of GGE sum of squares, respectively, explaining a total of $65.43 \%$ of the variation (Fig. 2). This revealed differential yield performance among the durum wheat genotypes across the treatments due to the presence of genotype-by-environment interaction $(\mathrm{G} \times \mathrm{E})$. To visualize the relationship between environments, lines known as environment vectors were drawn to connect the test environments to the biplot origin. Based on the vector positions, the rain-fed regimes of the dry 2011 and 2012 growing seasons formed a single group, while the treatments in the rainy year of 2013 formed another group with the irrigated treatment in 2012 . 
Table 1 Analysis of variance and repeatability for the investigated traits of 97 spring durum wheat genotypes under rain-fed and irrigated conditions in Martonvásár in 2011, 2012 and 2013

\begin{tabular}{|c|c|c|c|c|c|c|}
\hline Year & Genotype & Treatment & Gen.xTrt & Mean (Rainfed) & Mean (Irrigated) & h2 \\
\hline \multicolumn{7}{|c|}{ Yield $(G Y)(t / h a)$} \\
\hline 2011 & $<.001$ & $<.001$ & 0.009 & 3.16 & $4.74 * * *$ & \multirow{3}{*}{0.5345} \\
\hline 2012 & $<.001$ & $<.001$ & $<.001$ & 3.24 & $3.80 * * *$ & \\
\hline 2013 & $<.001$ & 0.057 & 0.005 & 3.13 & 3.18 & \\
\hline \multicolumn{7}{|c|}{ Thousand-kernel weight TGW ( $g$ ) } \\
\hline 2011 & $<.001$ & $<.001$ & 0.159 & 50.55 & 51.87 & \multirow{3}{*}{0.8494} \\
\hline 2012 & $<.001$ & $<.001$ & 0.115 & 48.39 & $41.72 * * *$ & \\
\hline 2013 & $<.001$ & $<.001$ & $<.001$ & 44.81 & 39.75 & \\
\hline \multicolumn{7}{|c|}{$\begin{array}{l}\text { Heading date (HD) (days from 1st of } \\
\text { January) }\end{array}$} \\
\hline 2011 & $<.001$ & 0.840 & 0.001 & 142.11 & 142.08 & \multirow{3}{*}{0.8911} \\
\hline 2012 & $<.001$ & $<.001$ & 0.437 & 138.73 & 137.41 & \\
\hline 2013 & $<.001$ & $<.001$ & 0.999 & 149.50 & 149.20 & \\
\hline \multicolumn{7}{|c|}{ Protein content $(P)(\%)$} \\
\hline 2011 & $<.001$ & $<.001$ & 0.317 & 11.61 & 12.63 & \multirow{3}{*}{0.8447} \\
\hline 2012 & $<.001$ & $<.001$ & 0.976 & 13.72 & 14.51 & \\
\hline 2013 & $<.001$ & $<.001$ & 0.004 & 14.79 & 14.30 & \\
\hline \multicolumn{7}{|c|}{ Test weight $(\mathrm{HL})(\mathrm{kg} / 100 \mathrm{dm} 3)$} \\
\hline 2011 & $<.001$ & $<.001$ & 0.001 & 82.44 & $80.93 * * *$ & \multirow{3}{*}{0.4475} \\
\hline 2012 & 0.017 & $<.001$ & 0.549 & 79.46 & $74.31 * * *$ & \\
\hline 2013 & $<.001$ & $<.001$ & $<.001$ & 84.02 & $80.48 * * *$ & \\
\hline \multicolumn{7}{|c|}{ Sedimentation index $Z(\mathrm{ml})$} \\
\hline 2011 & $<.001$ & $<.001$ & 0.192 & 39.79 & $45.30 * * *$ & \multirow{3}{*}{0.7862} \\
\hline 2012 & 0.006 & $<.001$ & $<.001$ & 79.42 & $74.74 * * *$ & \\
\hline 2013 & $<.001$ & $<.001$ & 0.012 & 56.82 & 53.34 & \\
\hline \multicolumn{7}{|c|}{ Gluten content $(G)(\%)$} \\
\hline 2011 & $<.001$ & $<.001$ & 0.776 & 24.76 & 27.61 & \multirow{3}{*}{0.7525} \\
\hline 2012 & $<.001$ & $<.001$ & 0.962 & 26.77 & 29.54 & \\
\hline 2013 & $<.001$ & $<.001$ & 0.001 & 31.76 & 30.44 & \\
\hline \multicolumn{7}{|c|}{ Plant high $(F L C)(\mathrm{cm})$} \\
\hline 2011 & $<.001$ & $<.001$ & 0.226 & 34.40 & 38.36 & \multirow{3}{*}{0.7310} \\
\hline 2012 & $<.001$ & $<.001$ & 0.109 & 27.43 & 35.17 & \\
\hline 2013 & $<.001$ & $<.001$ & 0.998 & 35.82 & 40.43 & \\
\hline \multicolumn{7}{|c|}{ Plant high $(B E)(\mathrm{cm})$} \\
\hline 2011 & $<.001$ & $<.001$ & 0.628 & 49.38 & $55.05^{*}$ & \multirow{3}{*}{0.7494} \\
\hline 2012 & $<.001$ & $<.001$ & 0.164 & 39.06 & $52.59 * * *$ & \\
\hline 2013 & $<.001$ & $<.001$ & 0.945 & 54.25 & 58.77 & \\
\hline \multicolumn{7}{|c|}{ Plant high $(T E)(\mathrm{cm})$} \\
\hline 2011 & $<.001$ & $<.001$ & 0.745 & 54.44 & 60.57 & \multirow{3}{*}{0.7309} \\
\hline 2012 & $<.001$ & $<.001$ & 0.149 & 42.93 & $58.08 * * *$ & \\
\hline 2013 & $<.001$ & $<.001$ & 0.925 & 58.89 & 64.70 & \\
\hline \multicolumn{7}{|c|}{ Ear lenght $(E L)(\mathrm{cm})$} \\
\hline 2011 & $<.001$ & $<.001$ & 0.124 & 5.06 & 5.53 & \\
\hline 2012 & $<.001$ & 0.012 & 0.128 & 3.77 & 5.58 & 0.4626 \\
\hline 2013 & 0.151 & $<.001$ & 0.015 & 4.50 & 5.90 & \\
\hline Fertile & & & & & & \\
\hline 2011 & 0.071 & 0.029 & 0.002 & 358 & $382 * *$ & \\
\hline 2012 & 0.981 & $<.001$ & 0.853 & 269 & $477 * * *$ & 0.4800 \\
\hline 2013 & $<.001$ & $<.001$ & 0.007 & 389 & $457 * * *$ & \\
\hline
\end{tabular}


Table 1 (continued)

\begin{tabular}{|c|c|c|c|c|c|c|}
\hline Year & Genotype & Treatment & Gen.xTrt & Mean (Rainfed) & Mean (Irrigated) & h2 \\
\hline \multicolumn{7}{|c|}{ SPAD45 } \\
\hline 2011 & $<.001$ & 0.502 & 0.008 & 44.78 & 45.11 & \multirow{3}{*}{0.7126} \\
\hline 2012 & 0.002 & 0.108 & 0.036 & 46.74 & 47.87 & \\
\hline 2013 & $<.001$ & 0.119 & 0.886 & 41.01 & 40.61 & \\
\hline \multicolumn{7}{|c|}{ SPAD65 } \\
\hline 2011 & $<.001$ & $<.001$ & 0.217 & 44.95 & 48.73 & \multirow{3}{*}{0.8382} \\
\hline 2012 & $<.001$ & 0.046 & 0.102 & 47.96 & 51.48 & \\
\hline 2013 & $<.001$ & 0.408 & 0.410 & 46.88 & 46.77 & \\
\hline \multicolumn{7}{|c|}{ SPAD77 } \\
\hline 2011 & $<.001$ & 0.043 & 0.514 & 41.90 & 46.19 & \multirow{3}{*}{0.7341} \\
\hline 2012 & $<.001$ & $<.001$ & 0.104 & 43.90 & $49.93 * *$ & \\
\hline 2013 & 0.008 & 0.027 & 0.239 & 36.51 & 40.10 & \\
\hline \multicolumn{7}{|c|}{ SPAD83 } \\
\hline 2011 & 0.874 & $<.001$ & 0.038 & 6.97 & $22.44 * * *$ & \multirow{3}{*}{0.4958} \\
\hline 2012 & 0.685 & $<.001$ & 0.145 & 7.10 & $27.76^{* * *}$ & \\
\hline 2013 & 0.636 & 0.029 & 0.205 & 15.90 & $25.10 * * *$ & \\
\hline \multicolumn{7}{|c|}{ SPAD85 } \\
\hline 2011 & 0.194 & $<.001$ & 0.004 & 3.27 & $7.17 * * *$ & \multirow{3}{*}{0.0009} \\
\hline 2012 & 0.762 & $<.001$ & 0.426 & 3.05 & $14.82 * * *$ & \\
\hline 2013 & 0.383 & $<.001$ & 0.605 & 5.25 & $10.84 * * *$ & \\
\hline \multicolumn{7}{|c|}{ Seed width (SW) } \\
\hline 2011 & $<.001$ & $<.001$ & 0.322 & 3.32 & 3.36 & \multirow{3}{*}{0.4187} \\
\hline 2012 & $<.001$ & $<.001$ & 0.003 & 3.25 & 3.09 & \\
\hline 2013 & $<.001$ & $<.001$ & $<.001$ & 3.15 & 3.05 & \\
\hline \multicolumn{7}{|c|}{ Seed length (SL) } \\
\hline 2011 & $<.001$ & $<.001$ & 0.012 & 6.91 & 6.97 & \multirow{3}{*}{0.075} \\
\hline 2012 & $<.001$ & $<.001$ & 0.286 & 7.35 & 7.19 & \\
\hline 2013 & $<.001$ & $<.001$ & 0.985 & 6.85 & 6.72 & \\
\hline
\end{tabular}

To identify superior genotypes better adapted to drought conditions, the analysis focused on the rain-fed treatment. The Average Environments Coordinate (AEC) has the average coordinates of all the test environments, and the Average Environment Axis (AEA) passes through the AEC (represented by a small circle) and the biplot origin. Environment1 (2011) had better discriminating power as well as representativeness because it had a small angle with the AEA. Consequently, it was identified as a good testing environment for selecting widely adaptable, highyielding genotypes in dry conditions (Fig. 3).

The ranking biplot method was used to evaluate the genotypes based on both their mean performance and their stability across environments (Figure S1). The horizontal line (the abscissa) indicates higher mean yield across environments, while the vertical line (the ordinate) indicates to greater variability (poorer stability) in either direction. In all three years 'DP-133' had the highest mean yield, followed by 'DP-017', 'DP-061', etc.; 'DP-071'.
'DP-091' had a mean yield similar to the grand mean, while 'DP-127' had the lowest mean yield. When evaluating the stability, 'DP-042' was found to be highly unstable, whereas, 'DP-011' and 'DP-185' which were located exactly on the AEA, were extremely stable in the average of the three years.

2011 year appeared to be the most suitable for identifying optimal genotypes with great output (in the present case the most drought-tolerant). As visualised in the ranking biplot method, the highest yielder was 'DP-133' followed by 'DP-017' and 'DP-061', as was obvious due to the fact that environment had a small angle with the AEA (their rankings were almost identical). However, the most stable genotypes with high yield were 'DP-126' and 'DP-136' (Figure S2).

An ideal genotype should have both high mean performance and high stability across environments. An 'ideal' genotype (the centre of the concentric circles) is placed directly on the AEA ('absolutely stable') and has 'highest mean performance'. Therefore, genotypes located closer to 
Fig. 1 Principal component analysis of grain yield and its attributing traits in the rain-fed (a) and irrigated treatments (b). $A U S D C$ (area under SPAD value decline curve), $B E$ base of the ear, FLC flag leaf collar, $F T N$ fertile tiller number, $G$ gluten content, $G Y$ grain yield, $H D$ heading date, $H L$ test weight, $P$ protein content, $S L$ seed length, $S P A D$ SPAD unit (at five stages:45, 65, 77, 83, 85), SSI stress susceptibility index, $S T I$ stress tolerance index, $S W$ seed width, $T E$ tip of the ear, $T G W$ thousand-kernel weight, $V$ vigor (at two stages:29-31, 33), $Z$ sedimentation index
Factor 2 (10.29\%)

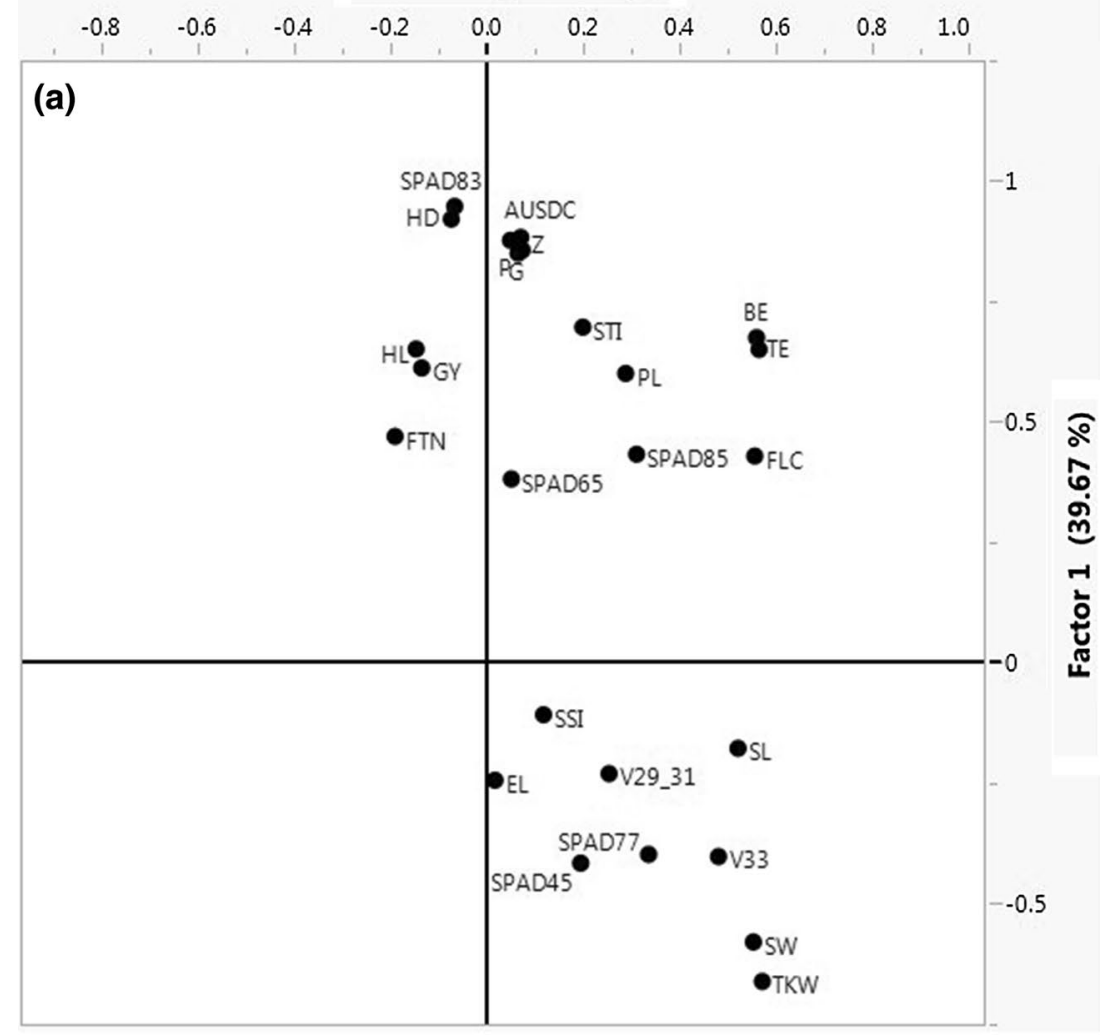

Factor 2 (10.4\%)

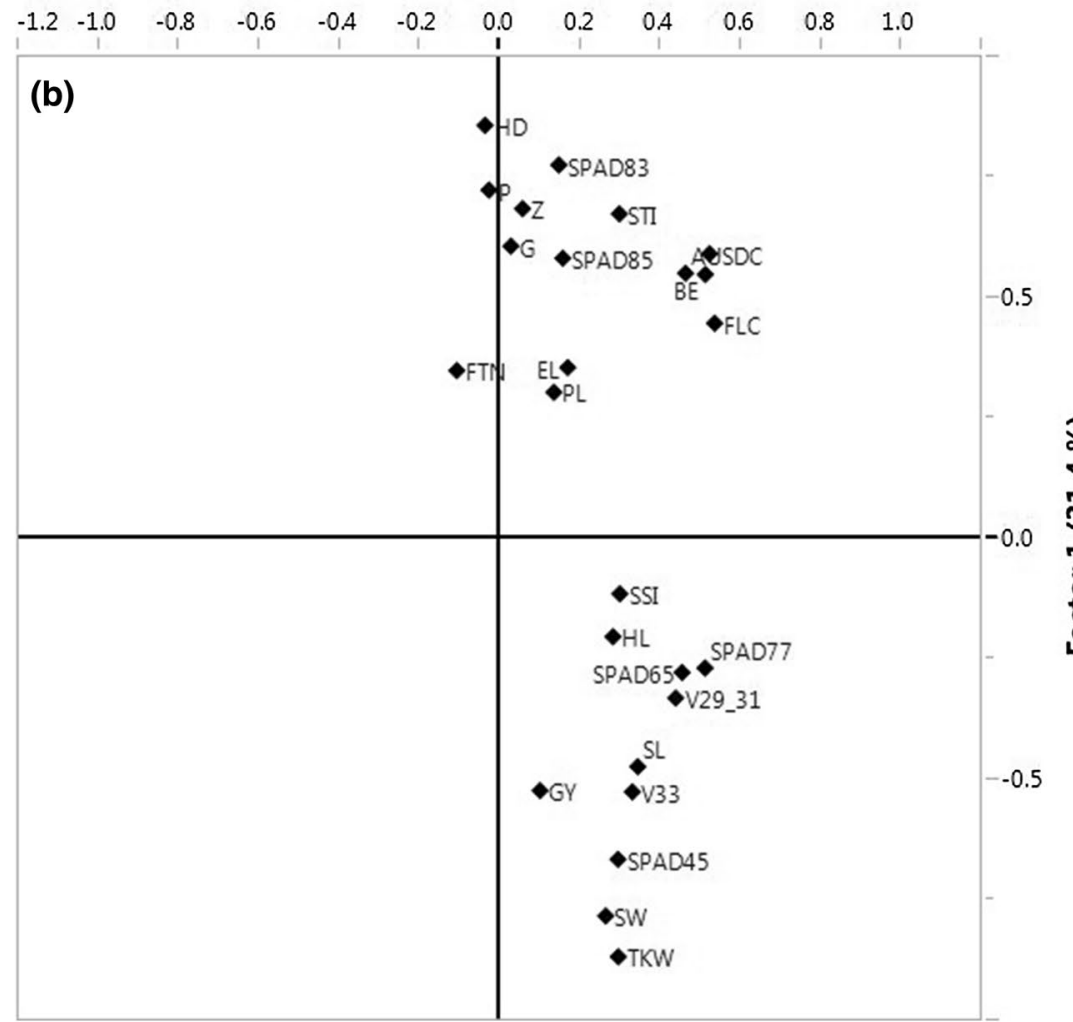


Fig. 2 Similarities between the treatments in the three years ( $R F$ rain-fed, $W$ irrigated)
Scatter plot (Total - $65.43 \%$ )

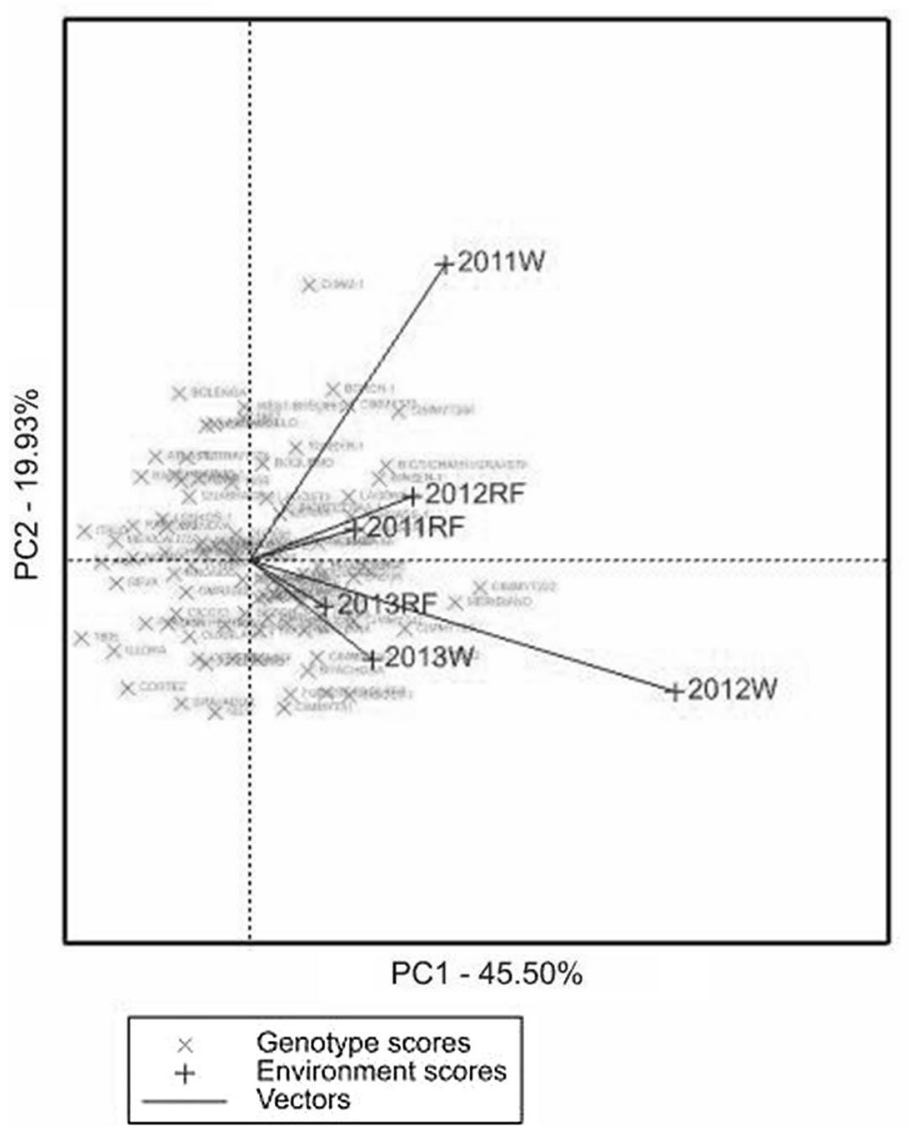

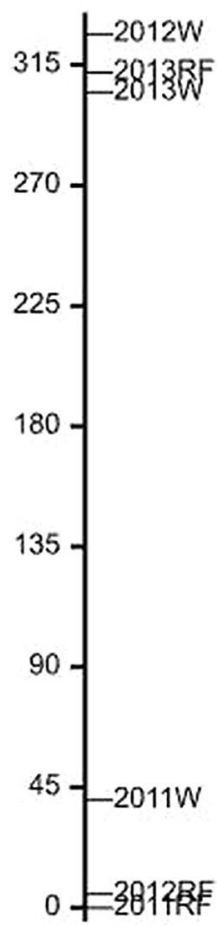

the'ideal' genotype are more desirable than others and preferable to select for the breeding programs. In the experiment, varieties 'DP-017', 'DP-118' and 'DP-126' proved to be the most desirable for breeding in the rain-fed replications despite the fact that variety 'DP-133' had the highest yield (Figure S3). Similar ranks were obtained using AMMI stability value (ASV) and yield stability index (YSI).

\section{Discussion}

Changes in total seasonal precipitation and its pattern of variability are both important, and the occurrence of moisture stress during flowering, pollination and grain-filling causes yield reduction in wheat (Habash et al. 2009). The aim is to breed drought-tolerant genotypes capable of producing satisfactory yields even in the case of water deficit due to their better water use efficiency and their better adaptation to water shortages and osmotic stress.

Stability in yield is the ability of a genotype to evade sizeable variation in yield over an array of environments. Consequently, in breeding programme, genotypes which have higher and stable yield are more desirable as candidate cultivars or as parents in crosses (Motzo et al. 2015).
However, differences in yield over environments $(\mathrm{G} \times \mathrm{E})$ hinder the gain from selection as they reduce the correlation between genotypic and phenotypic values and make it complicated to select genotypes that are widely adapted and stable (Shukla et al. 2015). In the present study, the year and the water supply level were shown to have the greatest effect on the morphology, physiology and yield biology of spring durum wheat genotypes, even in the case of traits with high repeatability $\left(\mathrm{h}^{2}\right)$. The only exception was the thousand-kernel weight, where the results of three years of drought stress proved the great stability of this parameter. Previous reports indicate that the effect of target environment on genotypic performance becomes more predictable when the breeding populations are subject to representative conditions over years and locations. Stability analysis is used not only to group environments based on the similarity of their effect on yield and yield components but also to identify genotypes exhibiting superior performance and stability in one or more groups of environments. As such, GGE biplot model applied in the present study was suited for stability analysis and was able to visualise graphically the genotypes that were more adaptable, i.e. drought tolerant across the three years. The biplot analysis showed that 'DP$133^{\prime}$ and 'DP-017' were the best cultivars in terms of yield, 
Fig. 3 Discriminating ability and representativeness of the rain-fed test environments. 1 : 2011; 2: 2012; 3: 2013

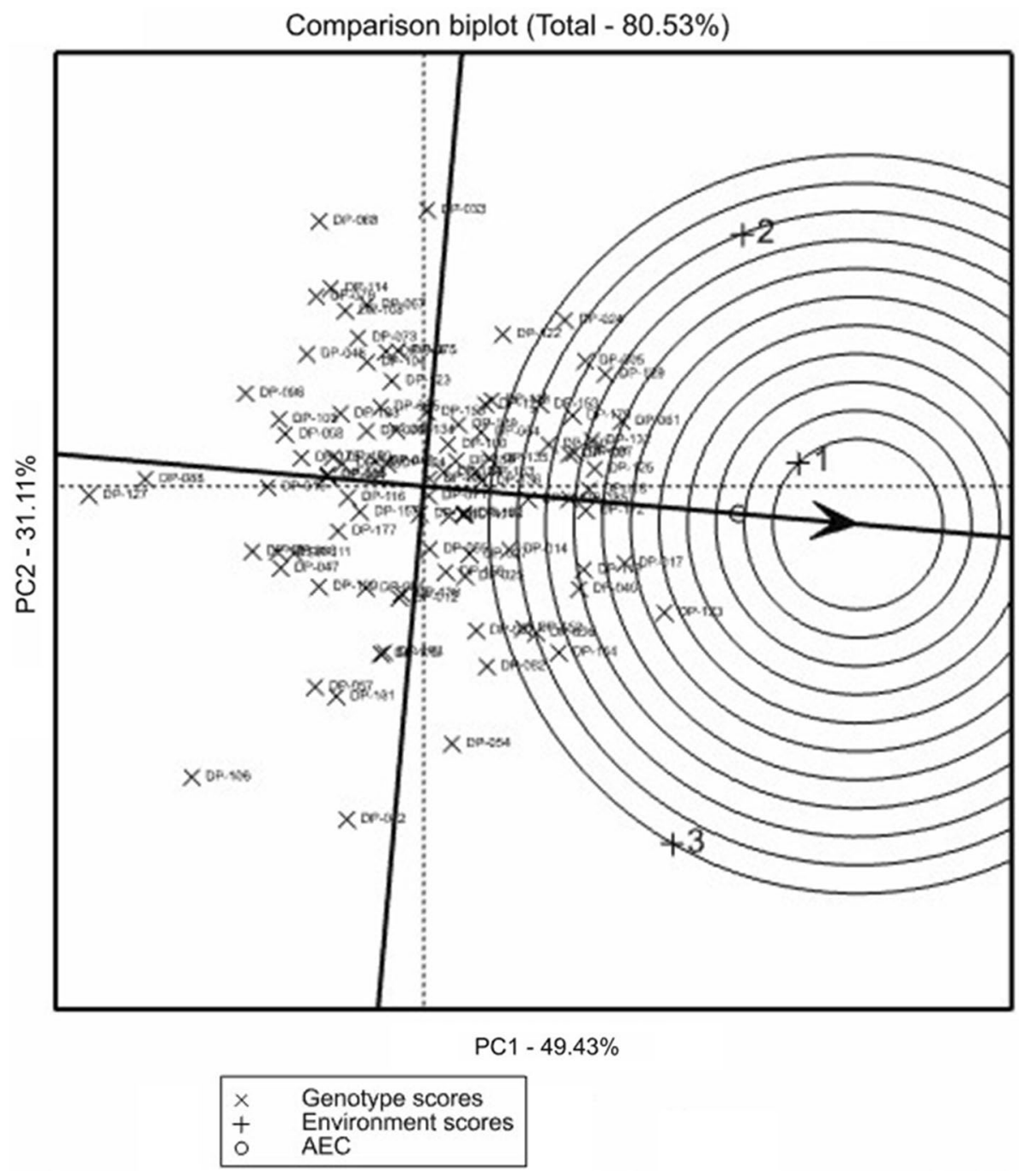

but that genotypes 'DP-011', 'DP-185', 'DP-126' and 'DP136 ' preceded them with their good stability. This result is in agreement with previous report by Pagi et al. (2017) that this procedure can effectively reveal genotype performance and stability. Similarly, Kendal (2019) identified mega environments for durum wheat in Turkey and identified stable and ideal genotypes for grain yield and quality traits suitable for such environments.

The present work further examined the effect of various combinations of multiple trait values on yield and yield stability under the study environment. The association of yield with plant height parameters, heading date and chlorophyll retention (SPAD83) in rain-fed treatment provides more opportunity for breeders to increase yield in predominantly rain-fed production. On the other hand, the consistent association between test weight and grain yield in both rain-fed and irrigated conditions suggest a possibility to improve both yield potential and yield stability.
Mohammadi (2019) applied genotype by yield*trait (GYT) biplot analysis to rank durum wheat varieties based on multi-trait values measured in multi-year trails under rain-fed conditions of Iran. The same work reported identification of breeding lines that possess better combination of agro-physiological characteristics and grain yield, making the approach valuable for breeders to select genotypes that combine multiple traits that contribute to high yield and stability.

Mohammadi et al. (2016) found that selection for high value kernel weight resulting from early flowering enhances yield stability in breeding lines, which is a major step towards adapting the increasing abiotic stress expected from the predicted climate change. The significant positive correlation between the SPAD values recorded in later phenophases (Z83, Z85) and yield shows that these phenophases exhibit the greatest variability between the genotypes under dry conditions. Many efforts have been made to determine 
the relationship between yield and vegetation indices. However, the results indicats that replicability is mostly limited by crop type, climate zone and year effects (Toscano et al. 2019), confirming our results.

The significant positive correlations revealed by principal component analysis between yield, fertile tiller number, and the hectolitre weight made it clear that these traits also contributed to the yield in the case of drought stress, so it is essential to take them into account during selection. In agreement with the report by Arduini et al. (2018), the plasticity in the number and yield of tiller spikes is crucial to respond positively to high yielding conditions, and to compensate for the lower yield of main culm spikes. These results provided further confirmation of the fact that selection for yield leads to the simultaneous selection of genes responsible for yield and abiotic stress adaptation (Richards 2006).

Identification of high yielding and stable genotypes has a substantial benefit to the regional breeding. Our work reinforces the need to evaluate genotypes under a representative test environment in order to realize this benefit. When multi environment trial is not possible, effective selection can be done on environment that has better representation and discriminating ability. In our case, selection based on one suitable year was indicative of performance on accross three years. The positive and negative associations between yield and component traits is also valuable information source parental lines and combine yield positive and stress adaptive traits in breeding programs. The use of multiple trait profile evaluated under target environment will help improve the gain from selection in variable environment.

Acknowledgements Open access funding provided by Centre for Agricultural Research. Funding from the EU FP7-244,374 DROPS and EU BONUS 12-1-2012-0017 projects is gratefully acknowledged.

Open Access This article is licensed under a Creative Commons Attribution 4.0 International License, which permits use, sharing, adaptation, distribution and reproduction in any medium or format, as long as you give appropriate credit to the original author(s) and the source, provide a link to the Creative Commons licence, and indicate if changes were made. The images or other third party material in this article are included in the article's Creative Commons licence, unless indicated otherwise in a credit line to the material. If material is not included in the article's Creative Commons licence and your intended use is not permitted by statutory regulation or exceeds the permitted use, you will need to obtain permission directly from the copyright holder. To view a copy of this licence, visit http://creativecommons.org/licenses/by/4.0/.

\section{References}

Ahamed KU, Nahar K, Fujita M (2010) Sowing date mediated heat stress affects the leaf growth and dry matter partitioning in some spring wheat (Triticum aestivum L.) cultivars. IIOAB 1:8-16
Araus JL, Slafer GA, Reynolds MP, Royo C (2002) Plant breeding and drought in $\mathrm{C} 3$ cereals: what should we breed for? Ann Bot 89:925-940

Arduini I, Pellegrino E, Ercoli L (2018) Contribution of main culm and tillers to grain yield of durum wheat: influence of sowing date and plant traits. Ital J Agron 13(1115):235-247

Balla K, Karsai I, Kiss T, Bencze S, Bedő Z, Veisz O (2012) Productivity of a doubled haploid winter wheat population under heat stress. Cent Eur J Biol 7(6):1084-1091

Bányai J, Karsai I, Balla K, Kiss T, Bedő Z, Láng L (2014) Heat stress response of wheat cultivars with different ecological adaptation. Cereal Res Commun 42(3):413-425

Behera UK, Sharma AR (2014) Productivity and water use efficiency of wheat (Triticum aestivum) under different resource conversation techniques and irrigation regimes. Cereal Res Commun 42(3):439-449

Budak H, Kantar M, Kurtoglu YK (2013) Drought tolerance in modern and wild wheat. Sci World J 2013:1-16

Dixit S, Singh A, Kumar A (2014) Rice breeding for high grain yield under drought: a strategic solution to a complex problem. Int J Agron 2014:1-15

Farshadfar E, Rashidi M, Jowkar MM, Zali H (2013) GGE Biplot analysis of genotype $\times$ environment interaction in chickpea genotypes. Eur J Experim Biol 3:417-423

Gauch HG (1988) Model selection and validation for yield trials with interaction. Biometrics 44:705-715

Gedif M, Yigzaw D (2014) Genotype by environment interaction analysis for tuber yield of potato (Solanum tuberosum L.) using a GGE biplot method in Amhara region. Ethiop Agric Sci 5:239-249

Habash DZ, Kehel Z, Nachit M (2009) Genomic approaches for designing durum wheat ready for climate change with a focus on drought. J Exp Bot 60:2805-2815

Haussmann BIG, Rattunde HF, Weltzien-Rattunde E, Traoré PSC, vom Brocke K, Parzies HK (2012) Breeding strategies for adaptation of pearl millet and sorghum to climate variability and change in west Africa. J Agro Crop Sci 198:327-339

Kendal E (2019) Comparing durum wheat cultivars by genotype $\times$ yield $\times$ trait and genotype $\times$ trait biplot method. Chil J Agric Res 79(4):512-522

Kiss T, Balla K, Bányai J, Veisz O, Karsai I (2014) Effect of different sowing times on the plant developmental parameters of wheat (Triticum aestivum L.). Cereal. Res Commun 42(2):239-251

Mohammadi R (2019) Genotype by yield*trait biplot for genotype evaluation and trait profiles in durum wheat. Cereal Res Commun 47(3):541-551

Mohammadi R, Farshadfar E, Amri A (2016) Path analysis of genotype $\times$ environment interactions in rainfed durum wheat. Plant Prod Sci 19(1):43-50

Motzo R, Pruneddu G, Virdis A, Giunta F (2015) Triticale vs durum wheat: A performance comparison in a Mediterranean environment. Field Crops Res 180:63-71

Pagi N, Prajapati N, Pachchigar K, Dharajiya D, Solanki SD, Soni N, Patel P (2017) GGE biplot analysis for yield performance of grain amaranth genotypes across different environments in western India. J Experim Biol Agric Sci 5(3):368-370

Pandey GC, Sareen S, Siwach P, Tiwari R (2014) Molecular Characterization of heat tolerance in bread wheat (Triticum eastivum L.) using differences in thousand-grain weights (dTGW) as a potential indirect selection criterion. Cereal Res Commun 42(1):38-46

Paul K, Pauk J, Geák Z, Sass L, Vass I (2016) Contrasting response of biomass and grain yield to severe drought in Cappelle Desprez and Plainsman V wheat cultivars. PeerJ 4:e1708. https ://doi.org/10.7717/peerj.1708 
Richards RA (2006) Physiological traits used in the breeding of new cultivars for water- scarce environments. Agric Water Manag 80:197-211

Rosielle AA, Hamblin J (1981) Theoretical aspects of selection for yield in stress and non-stress environments. Crop Sci 21:943-946

Seguin B (2010) Climate change and its impact on agricultural production, with a focus on the Mediterranean area. Options Méditerranéennes 95:9-18

Sharma RK, Osmanzai M, Singh RP, Braun HJ, Sharma RC (2013) Identification of high yield wheat genotypes through evaluation of international nurseries. Cereal Res Commun 42:303-313

Shukla S, Mishra BK, Mishra R, Siddiqui A, Pandey R, Rastogi A (2015) Comparative study for stability and adaptability through different models in developed high the baine lines of opium poppy (Papaver somniferum L.). Ind Crops Prod 74:875-886

Spitkó T, Nagy Z, Tóthné ZZ, Halmos G, Bányai J, Marton LC (2014) Effect of drought on yield components of maize hybrids (Zea mays L). Maydica 59:1-9

Tardieu F, Hammer G (2012) Designing crops for new challenges. Eur J Agron 42:1-2

Toscano P, Castrignano A, Filippo Di Gennaro S, Vonella AV, Ventrella, D., Matese, A. (2019) A precision agriculture approach for durum wheat yield assessment using remote sensing data and yield mapping. Agronomy 9(8):437

Yan W, Holland JB (2010) A heritability-adjusted GGE biplot for test environment evaluation. Euphytica 171:355-369 